\title{
Structure of Island Arcs
}

\author{
Bryan IsAcks \\ ESSA, Earth Sciences Laboratories and Lamont-Doherty Geological Observatory of \\ Columbia University Palisades, New York 10964
}

(Received January 12, 1970)

\begin{abstract}
Remarkable anomalies in the physical properties of the upper mantle are associated with the seismicity and volcanism of island arcs. The inclined zones of earthquakes, which reach depths of nearly $700 \mathrm{~km}$ in many regions, are associated with mantle material with anomalously high seismic wave velocities, low seismic wave attenuation, and perhaps high density. Studies of the orientations and magnitudes of the stresses that produce deep and intermediate-depth earthquakes suggest that the anomalous material contains the zones of mantle earthquakes, has a thin plate-like geometry, and is stronger and more dense than the adjacent mantle. In contrast, the uppermost mantle behind the island arc (the wedge-shaped region above the inclined zones of earthquakes) appears to have anomalously low seismic wave velocities, high seismic wave attenuation, and high heat flow. This anomalous region appears to extend several hundred kilometers behind the line of active volcanoes. These features all seem to be explainable by the tectonic model in which a slab of lithosphere descends into the mantle beneath an island arc. The lithosphere would be colder, and hence would have higher seismic velocities and lower attenuation and would be denser and stronger than the adjacent mantle. The wedge-shaped region above the descending slab would be heated up as a result of one or more processes (such as localized convection, frictional heating, or igneous activity) that result from the descent of the lithospheric slab.
\end{abstract}

